\title{
ALGUNAS REFLEXIONES A PROPÓSITO DE CIERTAS UNIDADES FRASEOLÓGICAS DE ORIGEN SEMÍTICO Y SU POSIBLE EVOLUCIÓN EN IBERORROMANCE
}

\author{
Yolanda Congosto Martín
}

\section{INTRODUCCIÓN}

1. Tal y como afirma Gloria Corpas Pastor en su Manual de fraseología, «la formación, el funcionamiento y el desarrollo del lenguaje están determinados no sólo por las reglas libres del sistema, sino también por todo tipo de estructuras prefabricadas de las que se sirven los hablantes en sus producciones lingüísticas» ${ }^{1}$. Estas estructuras, denominadas -entre otras posibles etiquetas- como unidades fraseológicas, constituyen una parte muy importante no sólo del léxico de una lengua, sino también del vocabulario de todo hablante, que siempre encuentra, dentro del amplio repertorio que conforman, la que se corresponde exactamente a las necesidades de cada situación concreta. Quién no ha utilizado alguna vez expresiones tales como: a ciencia cierta, a cal y canto, a otra cosa, mariposa, a mandar, a seguir bien, armar un escándalo, ¡A sí se habla!, arrojar la toalla, dorar la píldora, ir al grano, borrón y cuenta nueva, cada oveja con su pareja, con el corazón en la mano, de armas tomar, de tal palo, tal astilla, del tiempo de Maricastaña, derecho al pataleo, frío como el hielo, la madre que te parió, iya te acordarás!, ¡ya me las pagarás!... entre otras muchas más combinaciones de elementos que se han ido consolidando históricamente en el uso del español, y que tanto dicen de la idiosincracia de nuestra comunidad hablante y de sus peculiaridades culturales.

Desde un punto de vista lingüístico, quedan definidas como aquellas combinaciones estables de unidades léxicas que formadas por más de dos palabras gráficas en su límite inferior, y cuyo límite superior se sitúa en el nivel de la oración compuesta, se caracterizan por su polilexicalidad; por su alta frecuencia de uso y de coaparición de sus elementos integrantes; por su institucionalización o convencionalización derivada de su reproducción reiterada; por su estabilidad, entendida en términos de fijación (interna y externa) y de especialización semántica; por su idiomaticidad y variación potenciales; así como por el grado en el cual se dan estos aspectos en los distintos tipos.

Por los estudios realizados, sabemos además que estas unidades tienen una importancia capital en la adquisición y el procesamiento tanto de la lengua materna como de una segunda

1 Cfr. G. Corpas Pastor, Manual de fraseología española, Madrid, 1997, pág. 14. 
lengua. Efectivamente, a pesar de la dificultad que en su origen pueden ofrecer al hablante extranjero, me refiero concretamente a su comprensión semántica y a sus usos, una vez asimiladas éstas llegan a adquirir un lugar privilegiado dentro de su acervo lingüístico. De hecho, sólo tenemos que traer a nuestra memoria las numerosas expresiones, por ejemplo latinas, que aún conservamos en español: ad hoc, alma mater, a posteriori, a priori, curriculum vitae, ex cathedra, ex profeso, grosso modo, honoris causa, in albis, in extremis, in fraganti, in illo tempore, ipso facto, mare magnum, modus operandi, motu propio, per se, persona non grata, post mortem, sine qua non, statu quo, strictu sensu, sui generis, vox populi... por nombrar sólo algunas de las más utilizadas en nuestros cotidianos actos de habla.

Sin embargo, hoy quisiera llamar la atención sobre los ocho siglos de convivencia social y lingüística mantenidos con el pueblo árabe, y muy especialmente sobre el enriquecimiento léxico que ello supuso para la lengua castellana o española.

Como es sabido, la mayoría de las palabras árabes se han introducido en el castellano por factores no lingüísticos. Las nuevas realidades sociales y materiales incorporadas a nuestra realidad extralingüística necesitaban ser investidas de una forma lingüística, y el camino más cómodo, rápido y económico era tomar prestada la voz originaria, adaptándola a nuestras propias características lingüísticas estructurales. Y así, adquirimos innumerables voces pertenecientes a los más diversos campos léxicos: terminología relativa al mundo militar y de la caballería, a las instituciones administrativas y sociales, al reino animal y vegetal, a la indumentaria (vestidos, telas, adornos, joyas, perfumes, aderezos), a la medicina, al comercio, a las técnicas agrícolas y de construcción, a la música (instrumentos musicales), a los juegos, a las costumbres, y un largo etcétera.

En lo que respecta al mundo de la fraseología, y a pesar de su gran riqueza, son muy pocos los estudios realizados. Tanto R. Lapesa ${ }^{2}$ como F. Maíllo ${ }^{3}$, entre otros, han puesto de manifiesto cómo la adopción por los cristianos de prácticas sociales y culturales áraboislámicas dio lugar a una serie de calcos fraseológicos que reproducían de forma directa la estructura de un grupo de palabras árabes que conformaban fórmulas, sentencias breves, refranes, etc. Tal es el caso, por ejemplo, del siguiente refrán, aún hoy presente en los hablantes marroquíes, incorporado al texto del Corbacho: «Quando la barva de tu vezino vieres pelar, pon la tuya en remojo» ${ }^{4}$. Y de aquí, el extraordinario paralelismo, al menos en parte, entre los sistemas fraseológicos de ambas lenguas aún por estudiar de forma sistemática.

2 Cfr. R. Lapesa, «Los árabes y el elemento árabe en español», en: Historia de la Lengua española, Madrid, (9a reimpr.), 1997, págs. 129-156, y más concretamente el § 37 «Arabismo semántico, fraseológico y paremiológico».

${ }^{3}$ Cfr. F. Maíllo, Los arabismos del castellano en la baja Edad Media, Salamanca, 1991, págs. 491-493.

${ }^{4}$ En el caso de los refranes, véase, entre otros, E. García Gómez, «Hacia un «refranero» arábigo-andaluz», en: AlAndalus, XXXV y XXXVII, 1970-1972, y «Una prueba de que el refranero árabe fue incorporado en traducción al refranero español», Ibíd, XLII, 1977. 
Muchos son ya los investigadores ${ }^{5}$ que han subrayado cómo estas unidades, a pesar de ser fruto de situaciones socioculturales e históricas propias de cada comunidad, poseen un carácter universal, presentando similitudes que atañen no sólo a su tipología o a sus funciones léxicas, sino incluso al contenido de las mismas y a su forma, lo que nos posibilita el poder hablar de la existencia de lo que han dado en llamar universales fraseológicos. Y con mucha más razón en el caso que nos ocupa, dada la estrecha relación establecida a lo largo de la historia entre ambas culturas y ambas lenguas. Es lo que ocurre con expresiones como ${ }^{6}$ : desempeñar un papel $\rightarrow$ qama bi-dawrin, dársela a alguien con queso $\rightarrow$ ata bi-juffayn hunayn ${ }^{7}$, el que se pica ajos come $\rightarrow$ yahsibuna kulla sayhatan aleyhim ${ }^{8}$, cuéntaselo a tu abuela $\rightarrow$ dafanuka gariban ${ }^{9}$, etc.

Del mismo modo, Corpas Pastor también ha señalado cómo «dentro de los universales léxico-fraseológicos..., la presencia de palabras diacríticas entre los elementos integrantes de estas unidades, la formación de series a partir de un mismo constituyente base, las variantes fraseológicas y la existencia de idiomaticidad parcial e idiomaticidad total constituyen universales fraseológicos propios» ${ }^{10}$.

2. Así pues, si hacemos un recorrido por el catálogo fraseológico del que dispone nuestra lengua, y más concretamente por aquellas que perteneciendo a un mismo campo semántico hacen referencia a la divinidad, podremos darnos cuenta que éstas alcanzan un número muy considerable, pertenecientes, en su mayoría, a la esfera de los denominados enunciados fraseológicos, y dentro de ella, principalmente, a las llamadas fórmulas rutinarias: ¡me cago en Dios! 'fórmula para expresar enojo o insultar', jbendito sea Dios! 'exclamación de asombro, sorpresa, alivio', ¡Dios [me/te] libre (de algo)! o jlíbreme Dios! 'expresión con que se pondera lo absurdo o insensato que resulta hacer algo' o 'expresión enfática de prohibición', Dios dirá 'expresión que indica que se debe confiar el futuro al destino o a la voluntad de Dios’, ¡Dios me valga! o ¡válgame Dios!, ¡santo Dios! y ¡Dios mío de mi vida! 'exclamación de admiración, asombro, sorpresa, espanto o indignación', ¡Dios nos asista!,

5 Cfr. Roos, E., «Kontrastive Überlegungen zur deutschen, englischen und französischen Idiomatik», en: Sprache und Literatur in Wissenschaft und Unterricht, 56 (2), 1985, págs. 74-80; Dobrovol'skij,D.O., Phraeologie als Objekt der Universalienlinguistik. «Linguistische Studien». Leipzig, 1988; Corpas Pastor, G., Un estudio paralelo de los sistemas fraseológicos del inglés y el español, Málaga, 1995.

${ }^{6}$ Desde aquí quiero dar las gracias a Gloria Corpas Pastor por su amabilidad y por su ayuda. Los ejemplos citados a continuación están tomados de su artículo «Acerca de la (in)traducibilidad de la fraseología», en: Las lenguas de Europa: Estudios de fraseología, fraseografía y traducción, G. Corpas Pastor (ed.), págs. 483-522, y más concretamente las págs. 485 y 486, n.3, 4 y 5.

${ }^{7}$ Literalmente «llegar con las pantuflas de Hunayn». Procede de una antigua historia árabe.

${ }^{8}$ Literalmente «creen que todo grito va contra ellos». Es una sentencia coránica (Corán, LXIII).

${ }^{9}$ Literalmente «te han enterrado como a un extraño». Guarda relación con la costumbre musulmana de enterrar juntos a los miembros de una misma familia. Una interpretación aproximada del contenido referencial de esta fórmula podría ser la siguiente: «señal de que nadie te cree es que hasta te aíslan socialmente por tu mentira».

${ }^{10}$ Cfr. art. cit., pág. 487. 
¡que Dios nos coja confesados!, ino lo permitalquiera Dios! y ‘Dios nos tenga en su mano! 'exclamación de angustia o miedo', ¡Dios sabe! o jsabe Dios! 'expresión que indica la dificultad o imposibilidad de averiguar algo', i(que) Dios te/le maldiga! 'fórmula imprecatoria', i(que) Dios [te/se] lo pague! 'fórmula de agradecimiento', ique Dios te oiga! 'expresión que indica la esperanza que se tiene en que algo ocurra', gracias a Dios o a Dios gracia 'expresión o exclamación de alivio', 'afortunadamente', jvaya por Dios! 'exclamación que indica disgusto, compasión o lástima ante algún contratiempo', ipor el amor de Dios! 'fórmula empleada para pedir un favor o para excusarse con humildad' o 'exclamación que expresa enérgica protesta', i...que venga Dios y lo vea! 'expresión con que se pondera la falsedad o injusticia de una afirmación', ¡todo sea por Dios! 'expresión que indica conformidad o resignación ante algún contratiempo', [vete/vaya Vd.] con Dios 'expresión con que se despide o se saluda a alguien', Dios guarde a Ud. Muchos años 'fórmula de despedida', ¡Alabado/bendito sea Dios! 'expresión de enfado o de conformidad en un contratiempo'; aunque también nos encontremos con algunas paremias, fundamentalmente refranes: Dios los cría y ellos se juntan 'expresión con que se da a entender que los que son semejantes en las inclinaciones y en el genio se buscan unos a otros. Se usa generalmente peyorativamente' y A Dios rogando y con el mazo dando 'frase con que se recomienda que no se abandone a la ayuda de otros lo que uno puede hacerse por sí mismo'. Así como con otras unidades pertenecientes, en este caso, a la esfera de las locuciones: locuciones nominales: ni Dios 'nadie'; locuciones adjetivas: más ... que Dios 'muchísimo'; locuciones adverbiales: a la buena de Dios 'de cualquier forma, sin reflexiones', como Dios le da a entender, 'como buenamente puede, venciendo de cualquier modo las dificultades que se presentan', como Dios manda 'bien, como es debido', como Dios le trajo al mundo '[andar/estar] completamente desnudo', sin/no encomendarse ni a Dios ni al diablo 'sin/no pensarlo más', costarle Dios y ayuda 'costarle mucho trabajo'; locuciones clausales:[armar(se)] la de Dios '[provocar(se)] alboroto, escándalo, pelea', [estar] dejada(o) de la mano de Dios '[estar] descuidada, abandonada', [andar/ir] por esos mundos de Dios '[andar/ir] por diversos y/o múltiples lugares'; y, finalmente, locuciones conjuntivas: si Dios quiere 'si no surgen problemas o inconvenientes ${ }^{\prime 11}$.

Igualmente podremos encontrarnos en relación con éstas, aunque muy inferiores en número, algunas dirigidas a la Virgen: [ser un] viva la Virgen 'persona indolente, despreocupada', ;la virgen! 'expresión de sorpresa', ; Virgen Santísima! o ;Santísima Virgen! 'exclamación de susto, pena, protesta o súplica a la Virgen'12.

\footnotetext{
${ }^{11}$ Algunas de ellas son, precisamente, reproducciones de las fórmulas árabes correspondientes. Tal es el caso, por ejemplo, de que Dios guarde, que Dios mantenga (bendiciones que antaño acompañaban la mención del rey o señor), o el de si Dios quiere, Dios le ampare, e incluso el de exclamaciones tan "nuestras" como bendita sea la madre que te parió (Cfr. R. Lapesa, op. cit., pág. 155).

${ }_{12}$ Repertorio extraído del Diccionario fraseológico del español moderno realizado por F. Varela y H. Kubarth, Madrid, 1996.
} 
En cuanto a las unidades fraseológicas dirigidas a la divinidad en lengua árabe, la principal fuente documental es el Corán, libro sagrado que contiene «la palabra eterna e increada de Dios y, en consecuencia, única norma de conducta en esta vida, que les ha de llevar, al morir, a la eterna» ${ }^{13}$. Y de ahí, que sea precisamente en los estudios coránicos, además de en los lingüísticos ${ }^{14}$, donde se encuentran recogidas la inmensa mayoría de ellas.

De hecho, es una de ellas, la principal, la denominada basmala, la que abre todas y cada una de las azora (ar. al-sūra) del Corán: Bi-smi llähi l-rahmānil-rahìmi "En el nombre de Dios, el Clemente, el Misericordioso"; así como otras tales como: sallà llăhu "alà Muhammadin "Dios bendiga a Muhammad" (oración optativa), $\mathrm{Na}$ 'Iman "Que Dios te bendiga' (expresión que se le dice a quien acaba de darse un baño o de cortarse el pelo) ${ }^{15}$, además de ciertas fórmulas de cortesía: marhaban y ahlan wa-sahlan que pueden usar se tanto en función enunciativa como optativa: marhaban wa-ahlan wa-sahlan "Que Dios te haga encontrar [buena acogida y comodidad] allá donde te diriges" (or. optativa que se utiliza cuando alguien (un hombre) se dispone a salir de viaje), marhaban wa-ahlan wa-sahlan lo que vale como decir "Eso es lo que encontrarás bajo mi techo" (or. enunciativa que se utiliza cuando llega a tu casa un huésped $)^{16}$.

Pero no tratamos en esta ocasión de establecer un estudio comparativo de los sistemas fraseológicos de ambas lenguas. Nuestro interés se centra en el análisis de aquellas unidades fraseológicas árabes que, dirigidas a la divinidad, contienen expresamente el término Alá y su posible evolución en iberorromance.

A PROPÓSITO DE CIERTAS UNIDADES FRASEOLÓGICAS DE ORIGEN SEMÍTICO Y SU POSIBLE EVOLUCIÓN EN IBERORROMANCE

Si consultamos con detenimiento el Diccionario de Arabismos editado recientemente por Federico Corriente ${ }^{17}$, podremos detectar dentro de los innumerables préstamos en

${ }^{13}$ El Corán, introducción, traducción y notas de Juan Vernet, Barcelona, 1983, pág. XI.

${ }^{14}$ Cfr. lo que a propósito del tema manifiesta Salvador Peña en su artículo «El tratado de la frase por ibn al-Sĩd alBatalyawsī, en: Miscelánea de Estudios Árabes y Hebraicos, 42-43(1), 1993-1994, págs. 203-218.

${ }^{15}$ Cfr. El-Sayed, A., «Politeness Formulas in English and Arabic: A Contrastive Study», en I.T.L. Review of Applied Linguistics, 89-90, 1-23, y esta fórmula en concreto, en la pág. 9.

${ }^{16}$ Cfr. Salvador Peña, art. cit., págs. 213-215.

${ }_{17}$ Nos estamos refiriendo a su Diccionario de Arabismos y voces afines en iberorromance de reciente aparición, Madrid, 1999. De ahora en adelante será citado $D A$. 
iberorromance ciertas voces procedentes de unidades fraseológicas dirigidas a la divinidad. Algunas de indiscutible origen semítico, otras, posiblemente también, aunque habrá que seguir investigando en esta dirección para clarificar los datos con los que contamos. Es nuestra intención recogerlas en este artículo y analizar lo que a propósito de ellas manifiestan los distintos diccionarios.

¡Alalimón! (al alimón, a la limón, alá limón, alálimon, alálimo) Bajo esta entrada, el DHLE nos ofrece tres acepciones: 1. 'Juego de niños en que, divididos en dos bandos y asidos de las manos los de cada uno, se colocan frente a frente y avanzan y retroceden cantando alternadamente unos versos que empiezan con el estribillo alalimón, alalimón'. 2. adv. Conjuntamente. 3. Adv. 'que se dice de la suerte del toreo en que los lidiadores, asiendo cada cual de uno de los extremos de un solo capote, citan al toro y lo burlan, pasándole aquel por encima de la cabeza. Ú.t. en sent. fig.

De estas tres acepciones, es la primera la que en este momento nos interesa. Aparece documentada por $1^{a}$ vez en 1873: BORAO, Dicc. Voces Arag. Se trata de un juego infantil muy conocido en toda España, desde Álava y Vizcaya, hasta Aragón, Extremadura, Andalucía y parte de Castilla, y cuya letra difiere en algo de unos lugares a otros. Si observamos los testimonios documentales aportados de la misma, podremos ver que ésta presenta variaciones tanto gráficas como prosódicas: 1882 RDzMARÍn Cantos popul. I, 100: Alálimo, Ibíd, 168: A la limón; 1892 MugicA, P.Dialecto vizcaíno, 56: Alálimon; 1896 MARCO, L. y OCHOA, E.Repert juegos 857 b: A la limón; 1918 NAVARro Tomás céd. Ac.: En la Roda y Badajoz se dice: alá limón; 1919 Sevilla, A. VMurciano: Alalimón; 1920 TORO GISBERT Voces andal.: Alálimo; 1952 IrIBARREN VNavarro: Alálimon; 1992 DRAE alalimón, alimón (al). En lo que respecta a las variantes prosódicas, podremos ver que éstas oscilan entre una acentuación aguda o esdrújula.

Desde un punto de vista etimológico, ninguno de los diccionarios consultados, a excepción del de F. Corriente, se pronuncia al respecto; de hecho, el $D E C H$, ni siquiera la registra. Según F. Corriente la variante prosódica esdrújula podría confirmar la sospecha de que se trata de una frase árabe utilizada por titiriteros moriscos durante sus acrobacias. No es fácil recuperarla -manifiesta F. Corriente-, porque está corrupta y fonéticamente contaminada por el estándar limón, pero la acentuación navarra alálimon hace pensar, más que en una secuencia adverbial * Sala $+l \ldots$ 'sobre o por $x$ ', y aunque sea hipótesis muy atrevida, en algo así como alláh la yimún 'Dios no (lo) reproche', exclamación de ruego que los titiriteros musulmanes elevaban a la divinidad con el fin de que no se les reprochara el desarrollo de dicha actividad y la pirueta tuviera un final feliz, ya que toda acción que implique riesgo físico por mero propósito lúdico es condenada por la ortodoxia islámica (cfr. DA, s.v.).

¡Alleleví!, ¡Alalubí!, ¡Alálubi! (Ál. y Nav.) 'voz caprichosa que en este juego sirve de señal para que el que se queda salga a buscar a los demás'. Ál. y Nav. 'Juego del escondite' 
(DHLE, s.v.). Aparece documentada por primera vez en 1903 BARÁIBAR VÁlava, aleleví. 1918 céd. Ac.: alálubi [Localizado en Navarra], Alalubí [Localizado en Pamplona]. 1952 IRIBARREN VNavarro: Alálubi. 1992 DRAE aleleví Ál y Nav., e igual en Moliner, Dicc. Según F. Corriente (DA, s.v.), esta opaca voz sin fisonomía ni etimología vascas visibles, puede ser de procedencia romance meridional y, como en el caso de otros tecnicismos de juegos (alhuguí, alalimón y alirón, orí, zafaforate), guardar relación con los usados por los juglares, malabaristas y titiriteros mudéjares y moriscos. Aunque no pase de una hipótesis podría reflejar un juramento por el Profeta Muhammad y el califa guerrero ${ }^{\mathrm{C}} \mathrm{Ali}$, tomado por aquéllos de los combatientes en guerra santa y reducido a su forma más breve en andalusí falí (w)annabí, también podría pensarse sencillamente en andalusí cala + nnabí 'por el Profeta', o sea, confiando el éxito a su intercesión.

¡Aleluya! (cast.), ¡aleluia! (ct., gl. y pt.) 'Interjección jubilosa ritual': del lt. bíb. Hallęüia $<$ hb. hallęu yăh 'alabad a Dios' (DA, s.v.).

Como tal interjección, aparece documentada por primera vez en 1240-50 Alexandre (ms. P s. XV ed. 1934) v. 2400c. (DHLE s.v.).

En este caso, y como se puede comprobar en todos los diccionarios consultados, no hay la menor duda de que procede de dicho enunciado fraseológico.

¡Anda allá! (cs.) ‘expresión de incredulidad' y ¡anda lá! (pt) ‘interjección de exhortación, aviso o amenaza' ( $D A$, s.v.). En este caso, el hecho de que no se corresponda semánticamente con lo que debiera ser una orden de marcharse, ni entenderse tampoco muy bien por qué a un punto más o menos determinado, lleva a F. Corriente a apuntar la posibilidad de que estemos ante un residuo de la frecuente frase árabe ${ }^{c}$ inda llăhi (talqà) lhis āb 'ante Dios (encontrarás) la cuenta', con que se recrimina al que comete un exceso, hipótesis que podría se confirmada por la forma ¡anda! atestiguada como 'interjección para infundir miedo' en el Tesoro inédito de M. Alvar Ezquerra et al.

Según él, estamos ante expresiones o frases romances que tienen un significado muy diferente del que sugieren, por ser etimologías populares de otras andalusíes. Es el caso también de Ángela María. Tanto en una como en otra, la evolución de la lengua y la pérdida de conciencia del significado original han desembocado en una realidad distinta.

¡Ángela María!, ¡Angelamaría!:interjección que se usa para denotar aprobación, admiración, sorpresa, protesta, o el hecho de caer en la cuenta de algo (DHLE, s.v.). Aparece documentada en 1862 PICHARDo Dicc. voces cubanas s.v. anjá: Ángela María: mui bien, perfectamente. 1885 CUERVo Apunt. Leng. Bogot. 303: En Cuba se dice en algunas partes y es cosa que también se oye entre nosotros, Ángela María como interjección para denotar que se aprueba alguna cosa o que se cae en la cuenta de algo. 1894 GAICAZBALCETA 
VMexicanismos, la registra con el mismo sentido en Méjico y en Bogotá. 1897 ZEROLO Legajo162, con valor asertivo: Así es. También expresa admiración. 1911 SEgoviA Dicc. Argent. 653a: Interj. fam. de admiración, de sorpresa o de protesta. 1924 MILLARES Léx. Gran Canaria: Exclamación que expresa aprobación, asentamiento. Pudiera traducirse por ¡Eso es!, ¡Muy bien!, ¡Gracias a Dios!. E igualmente aparece recogida en Alvarado, L. Glos. Bajo español Venez., SANTAMARÍA, Dicc. de Americanismos, SAlVAdor, G. Habla de Cúllar-Baza, etc. La Academia DRAE (1992) igualmente la recoge con el mismo significado.

Según F. Corriente, esta curiosa exclamación, usada para expresar alivio cuando se aclara una duda, podría responder a una romanización y cristianización, en ambiente mudéjar o morisco, del andalusí injilá almírya < cl. Injilā’u lmiryah 'disipación de la duda' (DA, s.v.).

A la babalà (ct., con las var. mall. a la babal-là, a la babal-lana y val. a la bovalà), loc. adv.: 'sense reflexió, obrant frívolament'; en cast.'de una manera infundada o irreflexiva', 'al tuntún', 'a tontas y a locas', 'a la buena de Dios', del ár. 'alà bāb allăh, lit. 'a la puerta de Dios', según F. Corriente, no porque 'puerta' signifique aquí el poder, como piensa Corominas: pròpiament 'a la mà de Déu, en poder de Déu'(DECat.s.v.), sino como referencia a las 'puertas de la providencia divina' ( $a b w a ̄ b u ~ r r i z q)$ de la tradición islámica, es decir, diferentes vías por donde llega y la esperan algunos, sin poner nada de su parte, que es a lo que alude el dicho (DA, s.v.). Aparece documentado por primera vez a principios del s. XIX (Labèrnia 1839; y en muchos escritores mallorquines y del Principat de mediados de dicho siglo)(DECat., s.v.). Según F. Corriente, del mismo origen es el ár. dejar a la bimbola, o sea, 'a la buena de Dios', con imālah intensa y/o alguna contaminación, al no ser ya entendido.

Según Corominas, estamos ante un arabismo transmitido por la lengua franca del Norte de Africa a los pueblos románicos a través del comercio mediterráneo. Es voz de uso desde los Pirineos orientales hasta Mallorca, Menorca y todo el país valenciano, y fue usada ya por los viejos escritores de la Renaixença en el Principat y en Mallorca. Igualmente, aparece registrada en algunos dialectos italianos y de la lengua d'oc. De hecho, aparece en Marsella y en zona provenzal próxima. Es voz de carácter dialectal, fundamentalmente siciliano y veneciano, alababalà «alla carlona, a benefizio di natura, alla balorda» (def. pel dicc. de Boerio), y de allí, al griego moderno alabàbula ( $\alpha \dot{\lambda} \alpha \propto \mu \pi \alpha \dot{\mu} \mu \pi o v \lambda \alpha$ ) «confusamente» (Gustav. Meyer, Romanische Lehnworte im Neugriechischen, p.7) (DECat, s.v.).

En cuanto a la etimología, parece ser que no hay duda de su origen arábigo, a pesar de que Wartburg, para quien estamos ante una expresión onomatopéyica $b a b$, expresión de 'estultícia', 'beneiteria' ( $F E W$, I, 193, n.8), no tomara en serio la etimología arábiga propuesta por Mistral (Tres. I, 200).

A balquena (mall.): del andalusí balqanác a que debió llegar a significar 'en abundancia', partiendo del sentido clásico de qañ̄ah 'contento del morigerado', a partir de expresiones como la usada por IQ 128/5/2, alláh yarzúqni alqanác a fíh 'Dios me otorgue el poder prescindir 
de ello'. De donde resulta que, al volver a usar esta voz obsoleta, los autores de la Renaixença, desconocedores de su étimo, la acentuaron incorrectamente, pues debe ser aguda. La ortografía correcta debía ser, pues, balcaná (DA, s.v.).

Alcover \& Moll la recogen con el mismo significado y como voz mallorquina, pero no nos aportan ninguna orientación etimológica. Usada casi exclusivamente en la loc. adv. $a$ balquena, 'en gran abundancia'.

Del mismo parecer es Corominas quien manifiesta textualmente: «'en abundància, a dojo', locució adverbial mallorquina, d'origen segurament aràbic, que proé sens dubte d'una de les innombrables locucions d'aquest valor, començant en $b$ al-, formades per l'àrab amb la preposisió $b$-, l'article al- i un substantiu, deu tractarse d'una expressió de l'àrab vulgar baleàric o hispànic, no ben identificada...» 1. ${ }^{a}$ doc.: 1858, Tomàs Aguiló (DECat. s.v).

Faramalha (pt.), faramalla (cs.) 'enredo o trapaza', 'charla abundante, rápida y sin sustancia', 'cosa de mucha apariencia y poca entidad', del ant. farmalio 'engaño, falsía', metátesis del b. latín hispánico malfarium 'crimen', resultado de un cruce de nefarium 'crimen nefando' con maleficum y otras palabras en male- de sentido semejante. 1. a doc.: farmalio, Cronicón Albeldense, a. 833; faramalla, DAut. (DECH, s.v.).

Moll (Supl., nº 1442, y BDLC XIII, 353-5) supone la voz faramalla catalanismo, derivado de feram 'muchedumbre ávida', derivado a su vez de FERUS 'fiero' (Corominas-Pascual no la creen probable).

Para F. Corriente (DA, S.v.) probablemente del andalusí harám álla (con reducción del nombre divino por eliminación de la última consonante. Fenómeno conocido en andalusí y resto del neoár.) < cl. harāmu llāh 'lo anatematizado por Dios', aunque manifiesta que es difícil precisar fechas y jalones.

Gualá (cs.) ‘ipardiez!', del andalusí wallá(h)<cl. wallăh 'por Dios' (DA, s.v.).

Corominas-Pascual (DECH, s.v.), nos remite, en este caso, a la voz ¡ole!, de la que nos dice: probablemente es lo mismo que el hole americano, empleado para llamar, variante de hola y hala, todas ellas de creación expresiva [...] en Andalucía olé. Sin embargo, Asín (BRAE, VII, 1920, 362-3) la deriva de la interjección arábiga wa llâh, ya que wa pudo cambiarse fonéticamente en $o$ (= ojalá < del ár. wa sa llâh) y la $\hat{a}$, en esta posición fonética, en $e$, puesto que esa era su pronunciación vulgar, por lo que no habría inconveniente en admitir el cambio de wa llâh en olé e incluso quizá en ole (fenómeno que ocurre en algunos compuestos donde el nombre de Alá entra a formar parte, trasladándose el acento a la sílaba penúltima, en el habla vulgar), y así, alterado el vocablo y olvidado el sentido propio, era fácil que pasara a boca de cristianos. De la misma opinión es la Academia, ya que en la última edición del DRAE (1992) -y desde 1914- nos hace derivar la forma ¡olé! del ár. wa-llăh. Evolución que censura 
F. Corriente ( $D A$, s.v.), y no sólo por razones fonéticas, -ya que nunca hay imālah o palatalización en la última vocal del nombre árabe de Dios, puesto que la impide la habitual velarización expresiva de $/ l l l$, ni es frecuente un resultado $/ o /$ de $/ \mathrm{wa} /$, aunque se produce en algunos topónimos del sudoeste peninsular-, sino incluso semánticas.

Según F. Corriente, la voz gualá no parece haber estado nunca realmente integrada al romance, sino meramente puesta en boca de arabófonos por propósito literario, en cambio de código directivo. Lo que nos lleva a diferenciar entre dos voces, a menudo, confundidas y entremezcladas; por un lado, gualá, evolución directa a partir de la forma arábiga waláh, y por otro lado, ole y olé, voces de origen expresivo, al igual que hola y hala, actualmente considerados como falsos arabismos.

Lilailla (cs. y gl.) y lilailas (pl., pt., sólo en Morais (Novo dicionário compacto da língua portuguesa, Lisboa, Confluência, $7^{\mathrm{a}}$ ed. De la $1^{\mathrm{a}}$ de 1961) 'treta': del ár. lāilāha illāallăh "No hay más dios que Dios", profesión de fe y grito de guerra de los musulmanes que, como se ve, ha experimentado evolución semántica, por ser dicho grito unísono, lanzado al entrar en combate, uno de los modos con que se pretendía desmoralizar al adversario. Esta voz ha sido -según F. Corriente- desde sus comienzos confundida por los cristianos con la voz lelilíi (lilililî) (cs.) 'griterío festivo o guerrero de los musulmanes'. Como su propia definición manifiesta, siempre se ha confundido la profesión de fe y el grito de guerra con el grito festivo procedente de la expresión yā laylīyā Sayñ̄' ‘qué noche, la mía!, ¡qué ojos, los míos’ con que empezaban muchos poemas ár., dial. o cl., cantados en las zambras. Confusión que Corriente aclara argumentando diversas razones: la primera, de índole religiosa: la que hace impensable que en un acto lúdico se gritara una profesión de fe; la segunda, de índole fonética: como ya vimos anteriormente, nunca la voz allāh ha sufrido imālah, que explicase la /íl final (lelilí) (DA, s.v.). Confusión que como podemos observar mantiene la Academia. De hecho, aún así las recoge el DRAE (1992): s.v. lilaila1 'Vocerío de los moros, lelilí'; s.v. lelilí (del ár. lāilăh illā Allāh, 'no hay dios sino Alá', que es la profesión de fe islámica [pronunciada con imela]) 'Grito o vocería que hacen los moros cuando entran en combate o celebran sus fiestas y zambras'.

Corominas-Pascual, s.v. lelilí, nos remite a la voz allarido, a partir de la voz castellana *alalido, cambiada en alarido por disimilación. Para ellos, estamos nuevamente ante una voz de creación expresiva, que ya existía en otras lenguas. Concretamente, en griego existía la voz

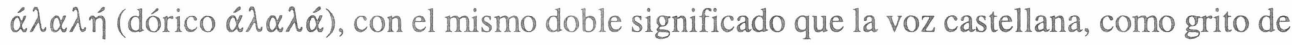
guerra al empezar el combate, y como grito de dolor y de alegría; en italiano, encontramos la voz alalà como grito fascista. En cuanto a la voz castellana estaría formada, de forma paralela, con el sufijo -ido típico de nombres de gritos (suponemos que se refiere a voces como: ronquido, estampido, gruñido, ladrido, maullido, etc. formadas con el sufijo-ido especializado para designar ruidos, sobre todo de animales). Desechan, por tanto, la etimología árabe (lâ ilâh illa allâh, propuesta por Baist), tanto por razones culturales-religiosas como fonéticas. Desde este último punto de vista, habría de partir de un étimo alali < *lalali $<*$ lalalalí $>>+$ el sufijo -ido, lo que haría igualmente suponer que el vocablo entró en castellano con la $\hat{a}$, pronunciada 
como $i$ por la imela granadina. Desde un punto de vista religioso, ya que parece ser que también era grito de guerra de los cristianos, y así documentada por primera vez en el Cid. En cuanto a su acepción 'grito lastimero de una persona', en el siglo XIII, en la $1^{a}$ Crón. Gral.

Por el contrario, el DHLE deriva la voz alarido 'grito de guerra de la tropa al entrar en batalla' del ár. al-garid 'la gritería'. Desde un punto de vista semántico, aparece recogida como $2^{a}$ acep. 'Grito lastimero de dolor, pena o susto', como $3^{a}$ acep. 'Grito de alegría' y como $4^{\mathrm{a}}$ acep. 'En general, cualquier grito fuerte o estridente'. E igualmente aparece en el $D R A E$, sólo que con un cambio de orden entre la acep. $3^{\mathrm{a}}$ y $4^{\mathrm{a}}$.

Por otro lado, el DAut. registra la variante lelilles 'Aquella grita o vocería que hacen los Moros, quando entran en alguna batalla o combate. Llámanse assi por que lo que pronuncian y se percibe es esta palabra Leli, leli, con que invocan su Propheta falso' (s.v. lelilles). En cuanto a la voz lilaila 'voz con que se explica lo impertinente, inútil, ridículo, o importuno, que dice o hace quien intenta estorvarnos, interrumpirnos o engañarnos: y suele decirse con buena Liláila se nos viene. Parece es tomado de lo que dicen freqüentemente los Moros en sus fiestas y necesidades'. Como podemos ver, si tomamos como cierta la definición y la etimología ofrecida por F. Corriente, estas dos definiciones tienen intercambiados sus contenidos semánticos. En cuanto a la voz alarido, nos dice 'grito mui alto y confuso, que según el tono, y las circunstancias en que se da y se oye, se concibe con diversos afectos: porque en las batallas, especialmente con las Naciones bárbaras, se toma por la grita o vocería que levantan al acometer, como hacen los Africanos de Berbería, y antiguamente los Griegos y los Romanos'.

Terreros recoge igualmente la voz lelilles (con la misma def. sem. que nos da el DAut.). En cuanto a la voz lilaila, la recoge aunque con otras acep. distintas a las vistas hasta ahora 'ridiculez, impertinencia, picardía, reserva, astucia, mañuela'. Tampoco en el caso de alarido, hace referencia alguna a los moros y a sus tipos de gritos; sólo nos dice 'grito o voz lamentable'.

En cuanto a Covarrubias, sólo recoge la voz alarido. Dozy, Gloss. 120, la relaciona con la voz algarada 'tumulto'. Y J. P. Machado (Boletim de Filol. VII, I-3), propone derivarla de 'arìd.

Noramala (cs.), adv. en hora mala loc. adv. que se emplea para denotar disgusto, enfado o desaprobación (DRAE, s.v.). Según F. Corriente (DA, s.v.), habría que ver su posible paralelismo con oxamala (pt. sólo en Morais), 'interjección de compasión': quizá metatético del andalusí *law ma šá lláh 'ojalá Dios no hubiera querido'. Por el contrario, para Corominas-Pascual, estamos ante un compuesto a partir del término hora: enhoramala [íd.; noramala, Quijote, Pícara Justina] (DECH, S.v.). 
Ojalá (cs.), ojualá (ar.), aojalá (mur.), oxalá (pt.), según F. Corriente, del andalusí law šá lláh < cl. law ša'a llah 'si Dios quisiera', con haplología. Manifiesta que dicha expresión está textualmente en IQ 74/1/1 y Azzajjālī núm. 1011. Y niega la etimología expuesta por la Academia en el DRAE y en el DECH: wašă'Allăh 'y quiera Dios' ya que es imposible sintácticamente.

CONCLUSIÓN

Como hemos podido comprobar, según las distintas incursiones realizadas en determinadas obras lexicográficas, tan interesante cuestión está necesitada de una profunda revisión y un detenido análisis.

En el caso de voces o expresiones como Aleluya y a la babalà, la etimología parece estar clara. Todos los diccionarios consultados al respecto así lo certifican. Bajos estas formas se esconden unidades fraseológicas de origen semítico dirigidas a la divinidad.

En cuanto a ojalá y a balquena parece que también, aunque no todos parecen coincidir en la unidad fraseológica originaria.

Con respecto a voces como lilaila, lelilí, faramalla y noramala, la opiniones parecen ser bastantes dispares, llegando incluso, en ocasiones, a ser totalmente caóticas.

En el caso de ¡anda allá! y ¡Ángela María!, creo que las aportaciones de F. Corriente no son del todo aceptables. En el caso de ¡anda allá!, creo, en primer lugar, que en realidad se trata más bien de la 'expresión enfática de rechazo categórico o violento, y de incredulidad' iandalvenga ya!. De la misma manera que tenemos ;Toma ya! 'expresión que indica asombro y sorpresa'. En segundo lugar, creo que en ninguno de los casos debe ser utilizado como argumento el sentido lógico de la expresión, deducible de la suma de los significados de las unidades que la conforman, que en realidad ya no posee. De todas formas, ambas puntualizaciones no impiden pensar que bajo ella subyaga oculta una expresión árabe relativa a la divinidad. En cuanto a Ángela María, y de acuerdo con la opinión del profesor Ariza, habría que tomar en consideración su posible procedencia a partir de la expresión religiosa de la anunciación «el ángel a María» ${ }^{18}$.

En el caso de gualá, y como muy bien puntualiza F. Corriente, nos encontramos ante una evolución directa a partir de la forma arábiga wallá $(h)<$ cl. wallăh 'por Dios' $>$.

${ }^{18} \mathrm{Cfr}$. la reseña que M. Ariza ha realizado a propósito de la publicación del nuevo Diccionario de Arabismos (DA) de F. Corriente en R.F.E. (en prensa). 
Y en el caso de alálimon y aleleví, sólo contamos con las interesantes hipótesis de F. Corriente.

Sin embargo, y a pesar de todo, para todas ellas nuestro autor encuentra la unidad fraseológica adecuada. En algunas ocasiones apuntadas con rotunda severidad; en otras, como meras hipótesis susceptibles de ser investigadas. Quien sabe, quizá algún día haya que matizar la afirmación realizada por Corominas-Pascual según la cual, y a excepción de ojalá, el árabe no prestó interjecciones al castellano, por lo menos con carácter permanente ${ }^{19}$.

BIBLIOGRAFÍA

Alcalá Venceslada, A., Vocabulario andaluz (VA), Madrid (reimpr. Gredos 1980).

Alcover \& Moll, Diccionari Català-Valencià-Ballear (AlcM), Palma de Mallorca, 1927 y ss.

Alonso, M., Diccionario Medieval Español, Salamanca: Univ. Pontificia, 1986.

Ariza, M. Diccionario de Arabismos y voces afines en iberorromance (Reseña) en: RFE, (en prensa).

Azkue, R.M. de, Diccionario vasco-español-francés, Bilbao, 1905.

Borao, J., Diccionario de voces aragonesas precedido de una introducción filológicohistórica, Zaragoza: Imprenta del Hospicio Provincial, 1908.

Casares, J., Diccionario ideológico de la lengua española, Barcelona: Gustavo Gili, 1959.

Cejador y Frauca, J., Vocabulario medieval castellano, Madrid, 1929.

El Corán, introducción, traducción y notas por Juan Vernet, Barcelona: Planeta, 1983.

Corpas Pastor, G., Un estudio paralelo de los sistemas fraseológicos del inglés y el español, Málaga, 1995.

Corpas Pastor, G., Manual de fraseología española, Madrid: Gredos, 1997.

Corpas Pastor, G., «Acerca de la (in)traductibilidad de la fraseología», en: Las lenguas de Europa: Estudios de fraseología, fraseografía y traducción, G. Corpas Pastor (ed.), Granada: Ed. Comares, 2000, págs. 483-522.

Corriente, F. Diccionario de Arabismos y voces afines en iberorromance (DA), Madrid: Gredos, 1999.

${ }^{19}$ DECH, s.v. ojalá 
Corominas, J., Diccionari etimològic i complementari de la llengua catalana, (DECat) Barcelona, 1983 y ss.

Corominas, J. y Pascual, J.A., Diccionario Crítico Etimológico Castellano e Hispánico, (DECH), Madrid: Gredos, 1987-1991.

Covarrubias Horozco, S. Tesoro de la Lengua castellana o española (Covarrubias), Madrid: Castalia, 1994.

Dobrovol'skij,D.O., Phraeologie als Objekt der Universalienlinguistik. «Linguistische Studien». Leipzig, 1988.

García Gómez, E., «Hacia un «refranero» arábigo-andaluz», en: Al-Andalus, XXXV y XXXVII, 1970-1972.

García Gómez, E. «Una prueba de que el refranero árabe fue incorporado en traducción al refranero español», en: Al-Andalus, XLII, 1977.

Iribarren, J.M., Vocabulario Navarro (VNavarro), $2^{\mathrm{a}}$ ed. prep. y amp. por R. Ollaquindia, Pamplona, 1984.

Lapesa, R. «Los árabes y el elemento árabe en español», en: Historia de la Lengua española, Madrid: Gredos, 1997 (9ª reimpr.), págs. 129-156.

Maíllo, F., Los arabismos del castellano en la baja Edad Media, Salamanca: Universidad, 1991.

Mistral, Frederi, Lou Tresor dóu Felibrige ou Dictionnaire Provençal-Français, 2 vols., Aix-en-Provence, 1878-86.

Peña, S., «El tratado de la frase por ibn al-Sĩd al-Batalyawsī, en: Miscelánea de Estudios Árabes y Hebraicos, 42-43(1), 1993-1994, págs. 203-218.

Real Academia, Diccionario de Autoridades (DAut.), (1726), Madrid: Gredos, 1984.

Real Academia, Diccionario de la Lengua Española (Di:AE), $21^{\mathrm{a}}$ ed., Madrid: EspasaCalpe, 1992.

Roos, E., «Kontrastive Überlegungen zur deutschen, englischen und französischen Idiomatik», en: Sprache und Literatur in Wissenschaft und Unterricht, 56 (2), 1985, págs. 7480.

El-Sayed, A., «Politeness Formulas in English and Arabic A Contrastive Study», en I.T.L. Review of Applied Linguistics, 89-90, 1-23.

Terreros y Pando, E., Diccionario castellano con las ces de ciencias y artes y sus correspondientes en las 3 lenguas francesa, latina e italian: Madrid: 1987 (reimp.).

Varela, F. y Kubarth, H., Diccionario fraseológico del est. ñol moderno, Madrid: Gredos, 1996. 
Wartburg, Walther von, Französisches Etymologisches Wörterbuch (FEW), vol. I (A-B) 1922-27. 
